\title{
Supporting Information: \\ A 2.5D reactive transport model for fracture alteration simulation
}

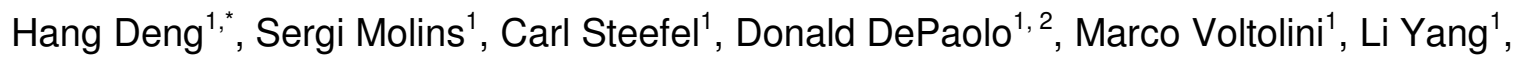
Jonathan Ajo-Franklin ${ }^{1}$

1. Lawrence Berkeley National Laboratory, Berkeley, CA, 94720

2. Earth and Planetary Science, University of California, Berkeley, Berkeley, CA, 94720

*email: hangdeng@lbl.gov, cell: 609-937-9927

\section{Table of Contents}

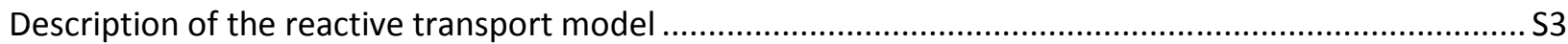

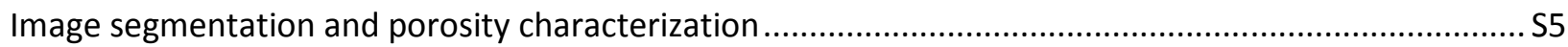

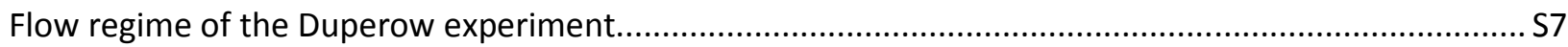

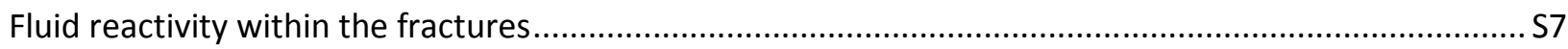

Sensitivity analysis of the spatial patterns of fracture alteration to different variables ..........................S8

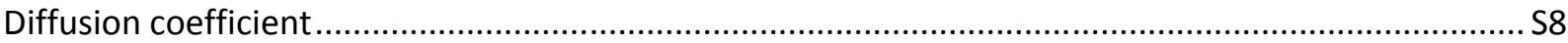

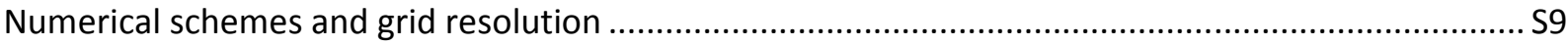

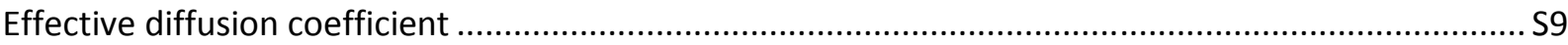

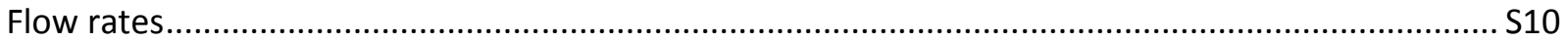

Diffusive boundary layer in comparison with the altered layer .................................................... S11

\section{List of figures}

Figure S1. (a) A cross-section of the reconstructed high resolution tomography image of a post-reaction subsample, (b) a slice of the high resolution tomography image at the location highlighted by the red dotted line, and the red dashed circle is the boundary used to crop the images for segmentation, (c) binary image of (b) after segmentation, where black corresponds to the pore space and white represents mineral phases, (d) porosity estimated from the binary images of the stack of grayscale images highlighted in the blue box in (a) (black dots - porosity for each 2D slice, black solid line average porosity for the entire subsection).

Figure S2. (a) 3D rendering of the post-reaction subsample used for the characterization of altered layer porosity, (b) a cross-section cutting through the subsample, showing the altered layer on the fracture surface (red box), (c) porosity estimated using the subsection of the high tomography images highlighted in the dashed blue box in (b) (black dots - porosity for each 2D slice, black solid line - average porosity for the entire subsection). 
Figure S3. pH values within the fracture plane at hour 20 of the simulations (a) without and (b) with the diffusion limitation of the altered layer on calcite dissolution.

Figure S4. Fracture aperture increase (top panel) and altered layer thickness $(\mathrm{mm})$ (bottom panel) at hour 113 for $D_{0}=0.8 \times 10^{-9} \mathrm{~m}^{2} / \mathrm{s}((\mathrm{a}),(\mathrm{c}),(\mathrm{e}),(\mathrm{g}))$, and $2.0 \times 10^{-9} \mathrm{~m}^{2} / \mathrm{s}((\mathrm{b}),(\mathrm{d}),(\mathrm{f}),(\mathrm{h}))$. The left and right two columns are results from the simulation without and with the altered layer diffusion limitation, respectively. S8

Figure S5. Fracture aperture increase (top panel) and altered layer thickness $(\mathrm{mm})$ (bottom panel) at the end of simulation for OS3D ((a), (c), (e), (g)), and grid size $27 \mu \mathrm{m}$ ((b), (d), (f), (h)). The left and right two columns are results from the simulation without and with the altered layer diffusion limitation, respectively.

Figure S6. Thickness of the altered layer $(\mathrm{mm})$ developed at hour 113 from the simulation with effective diffusion coefficient of (a) $1.0 \times 10^{-10} \mathrm{~m}^{2} / \mathrm{s}$ and (b) $0.4 \times 10^{-10} \mathrm{~m}^{2} / \mathrm{s}$................................................... S10 Figure S7. (a) Fracture aperture increase $(\mathrm{mm})$ and (c) altered layer thickness $(\mathrm{mm})$ at hour 600 from the simulation with flow rate of $1 \mu \mathrm{L} / \mathrm{min}$, and (b) fracture aperture change and (d) altered layer thickness at hour 60 from the simulation with flow rate of $10 \mu \mathrm{L} / \min ((b),(d))$. Both simulations account for the altered layer diffusion limitation. S10

\section{List of tables}

Table S1. Mineral reactions included in the reactive transport modeling of this study. The equilibrium constants are from EQ3/6 database. The kinetic parameters are from Deng et al. (2015) ${ }^{2}$ and Pokrovsky et al (2005) ${ }^{3}$.

Table S2. Aqueous complexation reactions involved in the reactive transport modeling of this study. The equilibrium constants are from EQ3/6 database. S4 


\section{Description of the reactive transport model}

In Crunchflow, the governing advection-diffusion-reaction equation is written for the total concentration of each component $\left(\psi_{i}\right)$ (eqn(S1)). The total concentration of component $i$ is the summation of the concentration of primary species $i$, and the contributions of all secondary species (with subscript $j$ ) that are formulated using primary species $i$ (eqn(S2)). The contribution of secondary species $j$ is weighted by the stoichiometric coefficient $v_{j, i}$ that relates secondary species $j$ to primary species $i$. The concentration of the secondary species $\left(C_{j}\right)$ is calculated from the concentrations of primary species based on aqueous complexation reactions, which are assumed to be at equilibrium. $K_{e q}$ is the equilibrium constant, and $\gamma$ is the activity coefficient that is calculated using the extended Debye-Hückle equation.

$$
\begin{array}{lr}
\frac{\partial\left(\phi \psi_{i}\right)}{\partial t}=-\nabla \cdot\left(\boldsymbol{u} \phi \psi_{i}\right)+\nabla \cdot\left(\phi \boldsymbol{D} \nabla \psi_{i}\right)-\sum_{m_{n}} v_{i, m_{n}} R_{m_{n}} & \text { eqn(S1) } \\
\psi_{i}=C_{i}+\sum_{j} v_{j, i} C_{j} & \text { eqn(S2) } \\
C_{j}=\gamma_{j}^{-1} K_{e q, j}^{-1} \prod_{i}\left(\gamma_{i} C_{i}\right)^{v_{j, i}} & \text { eqn(S3) }
\end{array}
$$

The temporal change of $\psi_{i}$ is attributable to (1) the advection term, where $\boldsymbol{u}$ is the Darcian flux, (2) the diffusion term, where $\boldsymbol{D}$ is the dispersion-diffusion tensor, and (3) the mineral reaction term. The reaction term accounts for the contribution from dissolution (negative) and precipitation (positive) reactions of minerals that involve primary species $i$, and $v_{i, m_{n}}$ is the stoichiometric coefficient of species $i$ in the reaction of mineral $m_{n}$.

The governing equations are discretized using the integrated finite difference method following the 2D mesh of the fracture plane. In our simulations, the governing equations are solved using the global implicit scheme (GIMRT), that is mineral reactions, complexation and transport are solved simultaneously in each time step. In our study, dispersion is not considered given that flow is resolved in relatively fine resolution, and diffusion is assumed to be isotropic and is represented by a scalar. Lateral diffusion in the fracture plane uses molecular diffusion coefficient $D_{0}$.

The minerals considered in this application include calcite and dolomite, and their reactions are treated kinetically. For dolomite dissolution, the surface-controlled reaction rate following the transition state theory (eqn(10)) is used; whereas for calcite dissolution, the surface-controlled reaction rate is only used for the simulations without the diffusion limitation of the altered layer, and the effective reaction rate (eqn(9)) is used for the simulations with the diffusion limitation of the altered layer. The solubility values $\left(K_{e q}\right)$ for the dissolution reactions written with respect to the primary species chosen in this study $\left(H^{+}\right.$, $\mathrm{H}_{2} \mathrm{CO}_{3}^{*}, \mathrm{Ca}^{2+}, \mathrm{Mg}^{2+}$ ) are summarized in Table $\mathrm{S} 1$, and are used in the calculation of the chemical affinity term in eqn(9). The kinetic coefficient for calcite dissolution is calculated based on the three parallel reaction mechanisms proposed by Plummer et al. (1978) ${ }^{1}$, using parameters that are reported in Deng et al. (2015) ${ }^{2}$ and are also summarized in Table S1. For dolomite dissolution, the elementary reaction involving $\mathrm{H}^{+}$is dominant, and the $\mathrm{pH}$ dependent kinetic coefficient is calculated using parameter reported in Pokrovsky et al $(2005)^{3}$ (Table S1). These studies are used because the values of the kinetic parameters reported were derived from experimental data collected under similar pressure conditions as the Duperow experiment. 
Table S1. Mineral reactions included in the reactive transport modeling of this study. The equilibrium constants are from EQ3/6 database. The kinetic parameters are from Deng et al. $(2015)^{2}$ and Pokrovsky et al (2005) ${ }^{3}$.

\begin{tabular}{|c|c|c|c|}
\hline Mineral & Reactions & $\log K_{e q}$ & $\log k\left(\mathrm{~mol} / \mathrm{m}^{2} s\right)$ \\
\hline Calcite $^{\mathrm{a}}$ & $\mathrm{CaCO}_{3}(\mathrm{~s})+2 \mathrm{H}^{+}=\mathrm{Ca}^{2+}+\mathrm{H}_{2} \mathrm{CO}_{3}^{*}$ & 8.16 & -1.08 \\
\hline & $\mathrm{CaCO}_{3}(\mathrm{~s})+\mathrm{H}^{+} \stackrel{k_{1}}{\Leftrightarrow} \mathrm{Ca}^{2+}+\mathrm{HCO}_{3}^{-}$ & & -3.96 \\
\hline & $\mathrm{CaCO}_{3}(\mathrm{~s})+\mathrm{H}_{2} \mathrm{CO}_{3}^{*} \stackrel{k_{2}}{\Leftrightarrow} \mathrm{Ca}^{2+}+2 \mathrm{HCO}_{3}^{-}$ & & -4.82 \\
\hline Dolomite $^{\mathrm{b}}$ & $\mathrm{CaMg}\left(\mathrm{CaCO}_{3}\right)_{2}(\mathrm{~s}) \stackrel{k_{3}}{\Leftrightarrow} \mathrm{Ca}^{2+}+\mathrm{CO}_{3}^{2-}$ & \\
\hline & $\mathrm{CaMg}\left(\mathrm{CO}_{3}\right)_{2}(\mathrm{~s})+2 \mathrm{Ca}^{2+}+\stackrel{k_{4}}{\Leftrightarrow} \mathrm{Ca}^{2+}+\mathrm{Mg}^{2+}+2 \mathrm{H}_{2} \mathrm{CO}_{3}^{*}$ & 15.21 & -3.35 \\
\hline
\end{tabular}

a. For the given reaction, the lonic Activity Production is calculated as follows: IAP calcite $=\frac{{ }_{\mathrm{Ca}^{2+} a_{\mathrm{H}_{2} \mathrm{CO}_{3}^{*}}}}{a_{\mathrm{H}^{+}}^{2}}$, where $a_{i}$ is the activity of species $i$. The three kinetic parameters $\left(k_{1}, k_{2}\right.$, and $\left.k_{3}\right)$ are used in eqn(11). Molar volume is $36.93 \mathrm{~cm}^{3} / \mathrm{mol}$.

b. For the given dolomite reaction: IAP dolomite $=\frac{a_{\mathrm{Ca}^{2+} \mathrm{M}_{\mathrm{Mg}} \mathrm{g}^{+} \mathrm{a}_{\mathrm{H}_{2} \mathrm{CO}}^{2}}}{a_{\mathrm{H}^{+}}^{+}}$, where $a_{i}$ is the activity of species $i$. The kinetic parameter $\left(k_{4}\right)$ is used in eqn(12). Molar volume is $64.37 \mathrm{~cm}^{3} / \mathrm{mol}$.

Complexation reactions of aqueous species are assumed to reach equilibrium instantaneously. The equilibrium constants for the reactions written with respect to the chosen primary species are summarized in Table S2.

Table S2. Aqueous complexation reactions involved in the reactive transport modeling of this study. The equilibrium constants are from EQ3/6 database.

\begin{tabular}{|c|c|}
\hline Aqueous complexation reaction & Log $\mathrm{K}_{e q}$ \\
\hline $\mathrm{HCO}_{3}^{-}+\mathrm{H}^{+}=\mathrm{H}_{2} \mathrm{CO}_{3}^{*}$ & 6.34 \\
\hline $\mathrm{CaOH}^{+}+\mathrm{H}^{+}=\mathrm{Ca}^{2+}+\mathrm{H}_{2} \mathrm{O}$ & 12.85 \\
\hline $\mathrm{Mg}_{4}(\mathrm{OH})^{4+}+4 \mathrm{H}^{+}=4 \mathrm{Mg}^{2+}+4 \mathrm{H}_{2} \mathrm{O}$ & 39.75 \\
\hline $\mathrm{OH}^{-}+\mathrm{H}^{+}=\mathrm{H}_{2} \mathrm{O}$ & 13.99 \\
\hline $\mathrm{CO}_{3}^{2-}+2 \mathrm{H}^{+}=\mathrm{H}_{2} \mathrm{CO}_{3}^{*}$ & 16.67 \\
\hline $\mathrm{CaCO}_{3}(\mathrm{aq})+2 \mathrm{H}^{+}=\mathrm{H}_{2} \mathrm{CO}_{3}^{*}+\mathrm{Ca}^{2+}$ & 13.35 \\
\hline $\mathrm{CaHCO}_{3}^{-}+\mathrm{H}^{+}=\mathrm{H}_{2} \mathrm{CO}_{3}^{*}+\mathrm{Ca}^{2+}$ & 5.30 \\
\hline $\mathrm{MgCO}_{3}(\mathrm{aq})+2 \mathrm{H}^{+}=\mathrm{H}_{2} \mathrm{CO}_{3}^{*}+\mathrm{Mg}^{2+}$ & 13.70 \\
\hline $\mathrm{MgHCO}_{3}^{-}+\mathrm{H}^{+}=\mathrm{H}_{2} \mathrm{CO}_{3}^{*}+\mathrm{Mg}^{2+}$ & 5.31 \\
\hline
\end{tabular}

The amounts of mineral reactions are used to update the mineral volume fractions $\left(V_{i, j, m_{n}}\right.$ in eqn(2)) based on the molar volume of the respective mineral (Table S1). The aperture of that mineral and local permeability are then updated using eqn(2) and eqn(1), respectively, for the solving of the governing equations in the next time step. 


\section{Image segmentation and porosity characterization}

High resolution tomography images were acquired for subsamples of the reacted core. The images were reconstructed at a voxel size of $1.6 \mu \mathrm{m}$, and are segmented for quantification of porosities of the altered layer and the intact rock matrix.

The images were first cropped to isolate the region of interest and eliminate surrounding background (Figure S1 (a) (b)). To characterize image pixels into either pore space or minerals, the iterative segmentation routine developed by Deng et al (2016) ${ }^{4}$ was used. Although the routine was devised for fracture characterization, the iterative approach improves the separability of pore space from mineral phases by adaptively using local information and is applicable in this study. First, the cropped 3D image was segmented using a threshold determined by Otsu's method. Second, the identified pore space is dilated, to create a mask for delineation of the domain for segmentation in the next step. Third, a new threshold is determined using the same method as step one, but based on the grayscale histogram of the pixels within the mask created in step two. The pore space produced in step 3 was compared with the old results that were used to generate the mask. If the difference is larger than a user specified value ( $1 \%$ in this case), step two and three are repeated. Otherwise, the iteration is terminated. Figure S1(c) shows an example of the segmented binary image.

The porosity is calculated as the ratio between the number of pixels classified as pore space and the total number of the pixels of the image analyzed. For instance, for the image shown in Figure S1 (b) and (c), the porosity is the calculated by dividing the number of black pixels by the number of pixels within the red dashed circle highlighted in Figure S1 (b). The porosity of a 3D domain is the averaged value of all the images within the domain.

For determination of the porosity of the intact rock, a subsample close to the outlet that is less affected by the reaction was used. To eliminate any impact of reactions on porosity, only a subsection of the images of the subsample that is beneath the altered layer and away from the fracture surface was included in the calculation. The results (Figure S1 (d)) showed that for the intact rock matrix, porosity varies between $8 \%$ and $11 \%$, with an average of $9.8 \%$. 


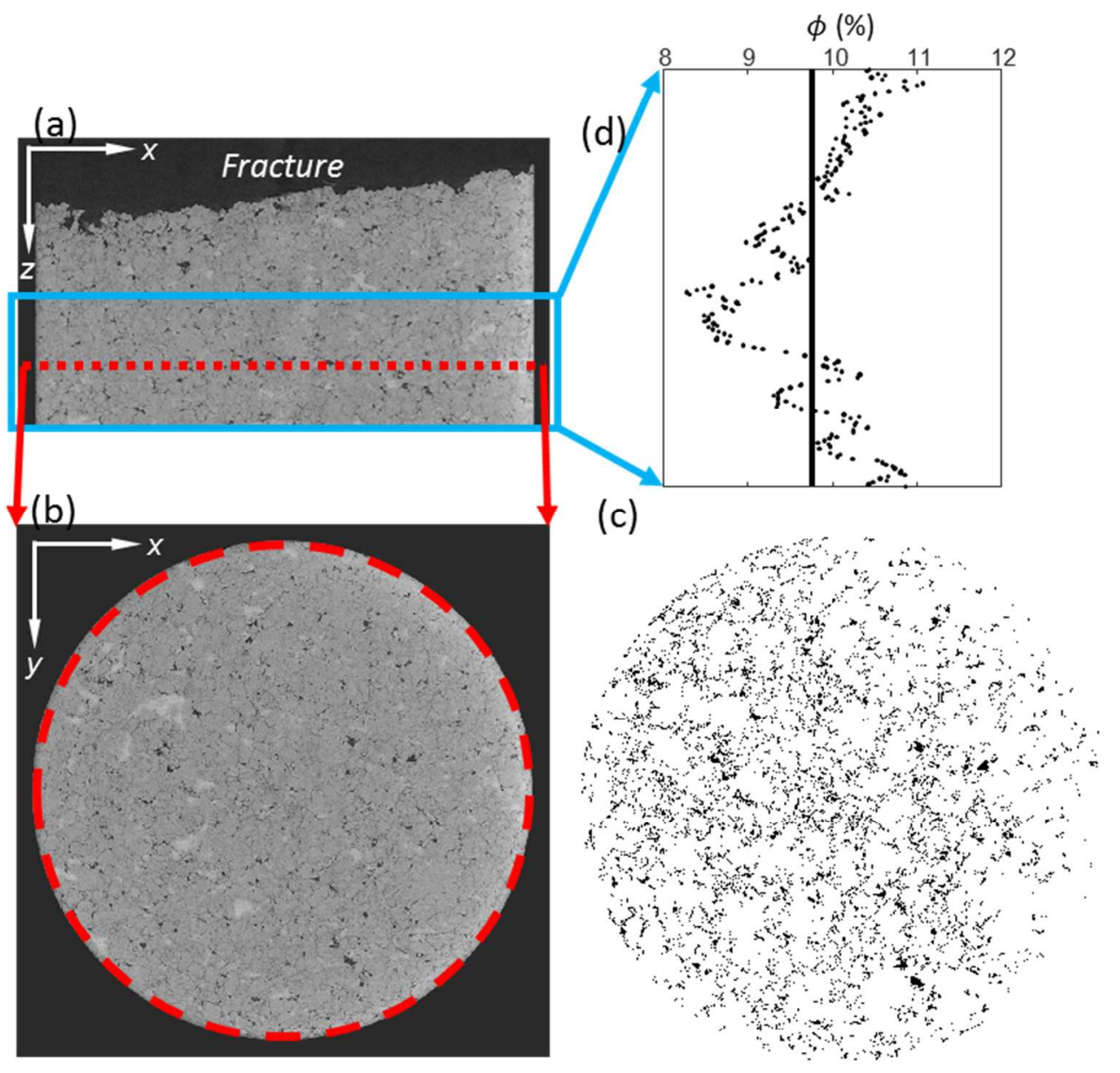

Figure S1. (a) A cross-section of the reconstructed high resolution tomography image of a post-reaction subsample, (b) a slice of the high resolution tomography image at the location highlighted by the red dotted line, and the red dashed circle is the boundary used to crop the images for segmentation, (c) binary image of (b) after segmentation, where black corresponds to the pore space and white represents mineral phases, (d) porosity estimated from the binary images of the stack of grayscale images highlighted in the blue box in (a) (black dots - porosity for each 2D slice, black solid line-average porosity for the entire subsection).

For analysis of the altered layer, the subsample (Figure S2) located at the upstream of the channel was chosen. The altered layer can be visually identified on the images. The red box in figure S2 (b) roughly outline the altered layer on a cross section of the sample. The altered layer is quite irregular and is not parallel to the exported image slices. To simplify image processing, a subsection of regular geometry as highlighted by the blue dashed box in Figure S2 (b) within the altered layer was selected for analysis. This also makes it easier to conduct proper porosity calculation. For the analyzed region within the altered layer, the averaged porosity is $28.9 \%$. Close to the fracture surface, the porosity reaches $36 \%$, and decreases as the distance away from the fracture surface increases. We note that these porosity estimates are valid only for the macroscopic porosity component above the image resolution. 


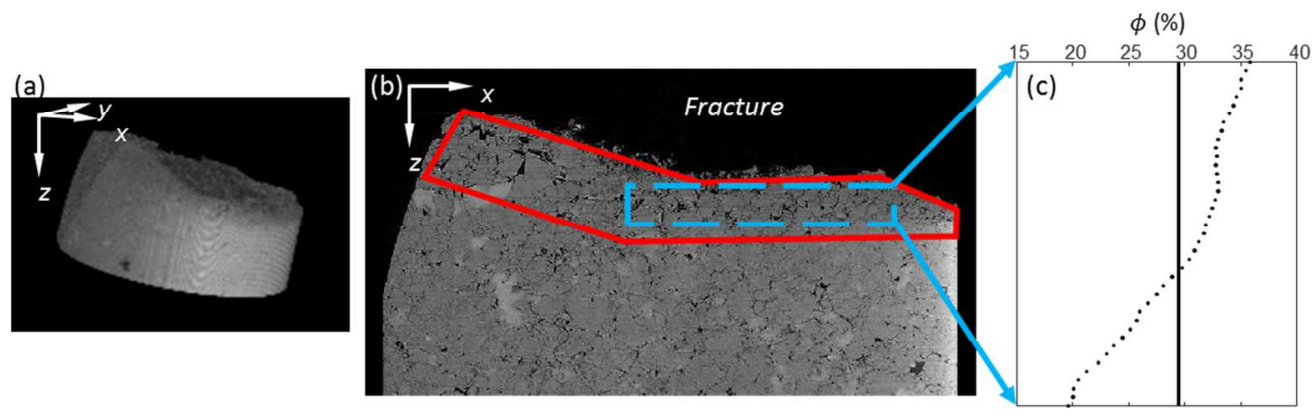

Figure S2. (a) 3D rendering of the post-reaction subsample used for the characterization of altered layer porosity, (b) a crosssection cutting through the subsample, showing the altered layer on the fracture surface (red box), (c) porosity estimated using the subsection of the high tomography images highlighted in the dashed blue box in (b) (black dots - porosity for each 2D slice, black solid line-average porosity for the entire subsection).

\section{Flow regime of the Duperow experiment}

The dimensionless Peclet number $(\mathrm{Pe})$ is used to measure the relative magnitude of advection and diffusion in the fracture (eqn(S4)). Based on the average flow velocity $(V)$, the initial average fracture aperture $(\bar{b})$, and the molecular diffusion coefficient $\left(D_{0}\right), P e$ for the experiment is estimated to be approximately 9 . The value is within the range reported for the development of channels.

$P e=V \bar{b} / D_{0}$ eqn(S4)

\section{Fluid reactivity within the fractures}

Figure $\mathrm{S} 3$ shows a snapshot of the fluid $\mathrm{pH}$ in the fracture plane, which provides an indication of fluid reactivity in the fracture. In the simulation without the diffusion limitation, calcite dissolution causes the $\mathrm{pH}$ to increase rapidly as the fluid flows downstream. In comparison, in the simulation with the diffusion limitation, the reactivity of the fluid is maintained further downstream, as lower $\mathrm{pH}$ is observed in a larger portion of the fracture along the flow direction.

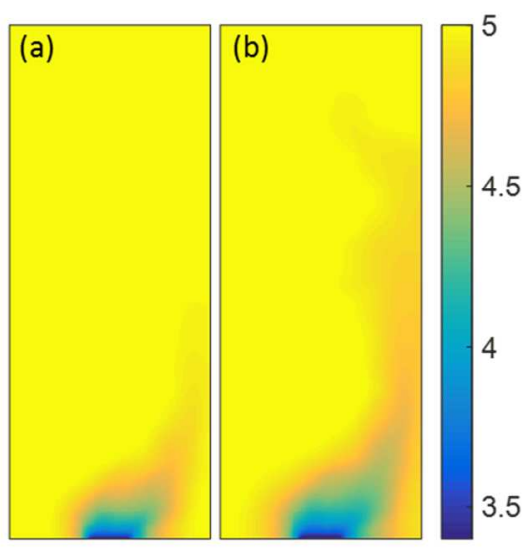

Figure S3. $\mathrm{pH}$ values within the fracture plane at hour 20 of the simulations (a) without and (b) with the diffusion limitation of the altered layer on calcite dissolution. 


\section{Sensitivity analysis of the spatial patterns of fracture alteration to different variables}

\section{Diffusion coefficient}

Free phase diffusion coefficients vary with species, temperature and pressure. Oelkers and Helgeson (1988) ${ }^{5}$ reported $\mathrm{Ca}^{2+}$ and $\mathrm{Mg}^{2+}$ diffusion coefficient varying between 0.8 to $0.9 \times 10^{-9} \mathrm{~m}^{2} / \mathrm{s}$ at $25^{\circ} \mathrm{C}$ under various pressures, while Rard and Miller (1979) ${ }^{6}$ measured diffusion coefficient ranging from 1.12 to $1.22 \times 10^{-9} \mathrm{~m}^{2} / \mathrm{s}$ for $\mathrm{Ca}^{2+}$. For carbonate and bicarbonate species, diffusion coefficients between 0.95 to $1.8 \times 10^{-9} \mathrm{~m}^{2} / \mathrm{s}$ were documented ${ }^{7,8}$. Here, the values of $0.8 \times 10^{-9} \mathrm{~m}^{2} / \mathrm{s}$ and $2 \times 10^{-9} \mathrm{~m}^{2} / \mathrm{s}$ were used to provide a lower and higher bound, respectively, to the possible diffusion coefficient values for the species present in the system. Except the diffusion coefficient, all other parameters are held the same in these simulations.

The spatial patterns of fracture aperture expansion and the altered layer are very similar for the given range of diffusion coefficients. The higher diffusion coefficient results in more diffused patterns across the fracture width, and more compacted variation along the flow direction. The differences, however, are insignificant compared to those observed between the simulation without and with the altered layer diffusion limitation.
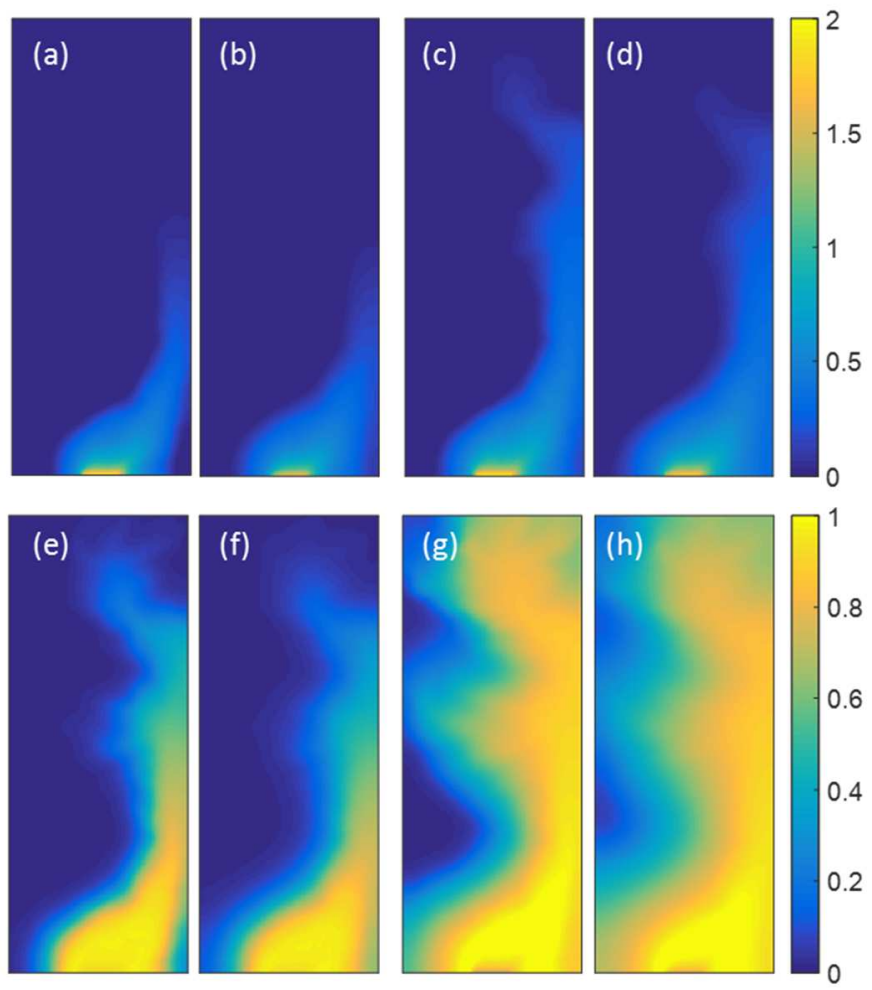

Figure S4. Fracture aperture increase (top panel) and altered layer thickness $(\mathrm{mm})$ (bottom panel) at hour 113 for $D_{0}=0.8 \times 10^{-9}$ $\mathrm{m}^{2} / \mathrm{s}((a),(c),(e),(g))$, and $2.0 \times 10^{-9} \mathrm{~m}^{2} / \mathrm{s}((b),(d),(f),(\mathrm{h}))$. The left and right two columns are results from the simulation without and with the altered layer diffusion limitation, respectively. 


\section{Numerical schemes and grid resolution}

In Crunchflow, the governing equations are discretized using the integrated finite difference method. Two numerical approaches are available for the coupling between transport and geochemical reactions. The global implicit scheme (GIMRT) allows the code to match in larger time steps and therefore reduce computational time, but may results in significant numerical dispersion. The operator splitting approach (OS3D), on the other hand, uses a third order accurate total variation diminishing (TVD) method that minimizes numerical dispersion. The trade-off, however, is that to maintain accuracy, time steps used in OS3D is limited by the Courant condition.

In our study, GIMRT was adopted in the simulations reported. This decision is justified by the relatively low flow rate in the fracture and the fine grid size used in the simulations, both of which contribute to reduce local Peclet number and the potential of numerical dispersion. As illustrated in Figure S5, further refining of the grid size or the use of OS3D instead of GIMRT only leads to small, and effectively negligible, differences in the predicted spatial patterns of fracture aperture change and altered layer development.
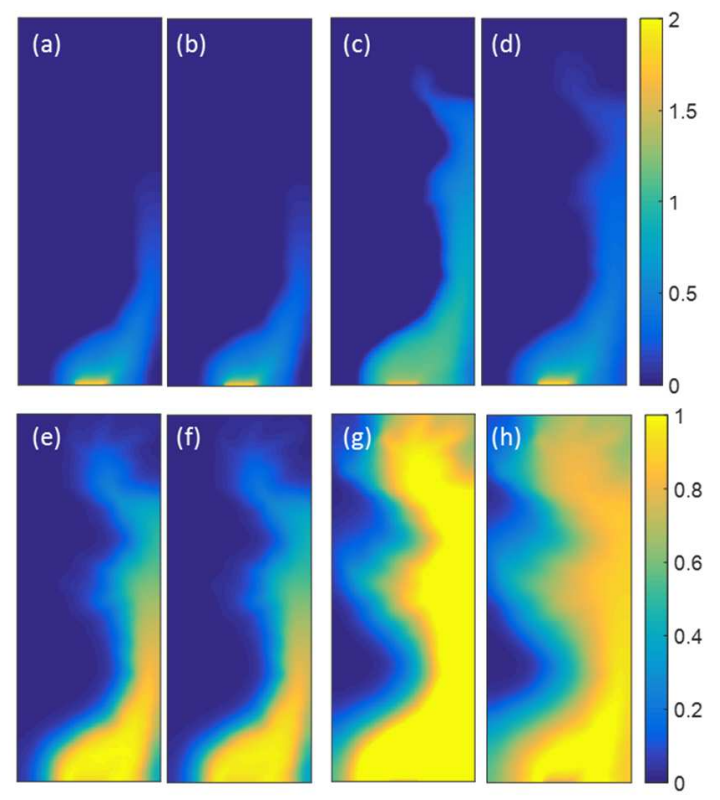

Figure S5. Fracture aperture increase (top panel) and altered layer thickness ( $\mathrm{mm}$ ) (bottom panel) at the end of simulation for $\operatorname{OS3D}((a),(c),(e),(g))$, and grid size $27 \mu \mathrm{m}((b),(d),(f),(h))$. The left and right two columns are results from the simulation without and with the altered layer diffusion limitation, respectively.

\section{Effective diffusion coefficient}

The effective diffusion coefficient affects the extent to which the extent of the dissolution of the fastreacting mineral is limited by the altered layer. However, the the spatial pattern of the altered layer is in general consistent among different $D_{\text {eff }}$ values. 


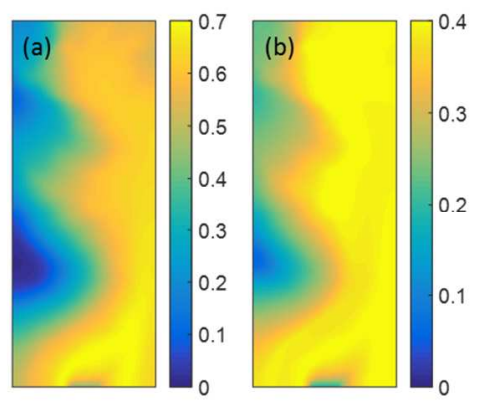

Figure S6. Thickness of the altered layer $(\mathrm{mm})$ developed at hour 113 from the simulation with effective diffusion coefficient of (a) $1.0 \times 10^{-10} \mathrm{~m}^{2} / \mathrm{s}$ and (b) $0.4 \times 10^{-10} \mathrm{~m}^{2} / \mathrm{s}$.

\section{Flow rates}

At a low flow rate, the spatial patterns of aperture increase and the altered layer are compacted at the inlet, the local aperture enlargement reaches $3.5 \mathrm{~mm}$, and the altered layer is approximately $2 \mathrm{~mm}$ thick close to the inlet. In comparison, at a high flow rate, the channel developed in the fracture goes through the fracture, and the majority of the fracture surface is coated with the altered layer, even though the average thickness is smaller than that of the low flow rate simulation.
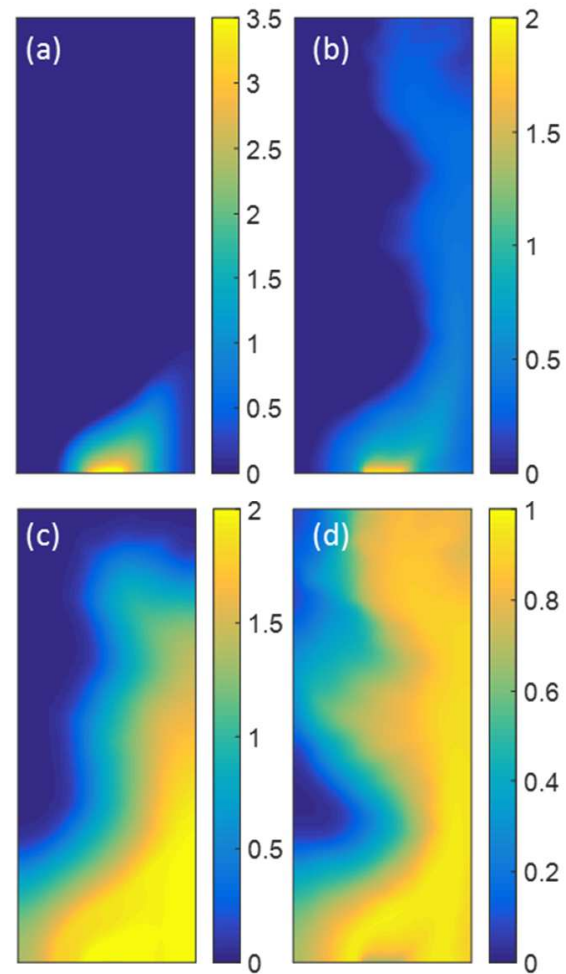

Figure S7. (a) Fracture aperture increase $(\mathrm{mm})$ and $(\mathrm{c})$ altered layer thickness $(\mathrm{mm})$ at hour 600 from the simulation with flow rate of $1 \mu \mathrm{L} / \mathrm{min}$, and (b) fracture aperture change and (d) altered layer thickness at hour 60 from the simulation with flow rate of $10 \mathrm{\mu L} / \mathrm{min}((b),(d))$. Both simulations account for the altered layer diffusion limitation. 


\section{Diffusive boundary layer in comparison with the altered layer}

The diffusion-controlled rate constants of the altered layer and the boundary layer are formulated similarly, and depend on the diffusion coefficient and the length scale of the layer. Therefore, comparing the length scales and diffusion coefficients of the boundary layer and the altered layer offers some insights regarding the relative contribution of the two diffusion limitations.

First, $D_{\text {eff }}$ used to describe the transport limitation of the altered layer is orders of magnitude lower than $D_{0}$ that describes diffusive transport in the boundary layer, because diffusion in the altered layer follows a more tortuous path that depends on the altered layer pore structure than is the case with the free diffusion in the fluid-only boundary layer. For example, values ranging from 1.3 to $6.4 \times 10^{-12} \mathrm{~m}^{2} / \mathrm{s}$ were measured in the altered surfaces of natural granite samples ${ }^{9}$. Even for the very porous and vuggy altered layer in our study, the value of $D_{e f f}$ is still approximately one order of magnitude lower than $D_{0}$.

Second, the altered layer is most likely thicker than the diffusion boundary layer. While the thickness of the porous altered layer is clearly defined by the physical system, determination of the thickness of the diffusion boundary layer is more challenging ${ }^{10}$. The thickness of the diffusion boundary layer depends on flow rates, fracture roughness, and surface kinetics, and has been reported to be on the order of $10 \sim 100 \mu \mathrm{m}{ }^{11,12}$. It was also pointed out that concentration gradients are unlikely to develop in single fractures under common hydrogeological conditions ${ }^{13}$, which indicates the absence of a diffusion boundary layer. In contrast, the thickness of the altered layer is often considerable. Experimental studies have reported the thickness to be 300-500 $\mu \mathrm{m}$ for an altered layer developed after 100 hours of reactive flow ${ }^{14,15}$. Furthermore, the measurements of $D_{\text {eff }}$ by Bradbury and Green (1986) ${ }^{9}$ indicated altered layer up to $10-15 \mathrm{~cm}$ thick on naturally weathered fissure surfaces.

Given the substantially lower diffusion coefficient and likely larger length scale of the altered layer, the diffusion limitation caused by the altered layer will be much more important than that associated with the diffusion boundary layer. Since the two transport limitations are additive, the system is controlled primarily by the larger one.

1. Plummer, L. N.; Wigley, T. M. L.; Parkhurst, D. L., KINETICS OF CALCITE DISSOLUTION IN CO2WATER SYSTEMS AT 5-DEGREES-C TO 60-DEGREES-C AND 0.0 TO 1.0 ATM CO $_{2}$. American Journal of Science 1978, 278, (2), 179-216.

2. Deng, H.; Fitts, J. P.; Crandall, D.; Mclntyre, D.; Peters, C. A., Alterations of Fractures in Carbonate Rocks by CO2-Acidified Brines. Environmental science \& technology 2015, 49, (16), 1022610234.

3. Pokrovsky, O. S.; Golubev, S. V.; Schott, J., Dissolution kinetics of calcite, dolomite and magnesite at 25 degrees $C$ and 0 to $50 \mathrm{~atm}$ pCO(2). Chemical Geology 2005, 217, (3-4), 239-255.

4. $\quad$ Deng, H.; Fitts, J. P.; Peters, C. A., Quantifying fracture geometry with X-ray tomography: Technique of Iterative Local Thresholding (TILT) for 3D image segmentation. Computational Geosciences 2016, 20, (1), 231-244.

5. Oelkers, E. H.; Helgeson, H. C., CALCULATION OF THE THERMODYNAMIC AND TRANSPORTPROPERTIES OF AQUEOUS SPECIES AT HIGH-PRESSURES AND TEMPERATURES - AQUEOUS TRACER DIFFUSION-COEFFICIENTS OF IONS TO 1000-DEGREES-C AND 5-KB. Geochimica Et Cosmochimica Acta 1988, 52, (1), 63-85. 
6. Rard, J. A.; Miller, D. G., MUTUAL DIFFUSION-COEFFICIENTS OF NACL-H2O AND CACL2-H2O AT 25-DEGREES-C FROM RAYLEIGH INTERFEROMETRY. Journal of Solution Chemistry 1979, 8, (10), 701-716.

$7 . \quad$ Li, Y. H.; Gregory, S., DIFFUSION OF IONS IN SEA-WATER AND IN DEEP-SEA SEDIMENTS. Geochimica Et Cosmochimica Acta 1974, 38, (5), 703-714.

8. Gaus, I.; Azaroual, M.; Czernichowski-Lauriol, I., Reactive transport modelling of the impact of CO2 injection on the clayey cap rock at Sleipner (North Sea). Chemical Geology 2005, 217, (3-4), 319-337. 9. Bradbury, M. H.; Green, A., INVESTIGATIONS INTO THE FACTORS INFLUENCING LONG-RANGE MATRIX DIFFUSION RATES AND PORE-SPACE ACCESSIBILITY AT DEPTH IN GRANITE. Journal of Hydrology 1986, 89, (1-2), 123-139.

10. Casey, W. H., HETEROGENEOUS KINETICS AND DIFFUSION BOUNDARY-LAYERS - THE EXAMPLE OF REACTION IN A FRACTURE. Journal of Geophysical Research-Solid Earth and Planets 1987, 92, (B8), 8007-8013.

11. Molins, S.; Trebotich, D.; Yang, L.; Ajo-Franklin, J. B.; Ligocki, T. J.; Shen, C.; Steefel, C. I., PoreScale Controls on Calcite Dissolution Rates from Flow-through Laboratory and Numerical Experiments. Environmental Science \& Technology 2014, 48, (13), 7453-7460.

12. De Baere, B.; Molins, S.; Mayer, K. U.; François, R., Determination of mineral dissolution regimes using flow-through time-resolved analysis (FT-TRA) and numerical simulation. Chemical Geology 2016, 430, 1-12.

13. Li, L.; Steefel, C. I.; Yang, L., Scale dependence of mineral dissolution rates within single pores and fractures. Geochimica Et Cosmochimica Acta 2008, 72, (2), 360-377.

14. Ajo-Franklin, J. V., Marco; Molins, Sergi; Yang, Li, Coupled Processes in a Fractured Reactive System: A Dolomite Dissolution Study with Relevance to GCS Caprock Integrity. In Caprock Integrity in Geological Storage : Hydrogeochemical and Hydrogeomechanical Processes and their Impact on Storage Security, Wiley Publishing: 2016; Vol. in review.

15. Noiriel, C.; Made, B.; Gouze, P., Impact of coating development on the hydraulic and transport properties in argillaceous limestone fracture. Water Resources Research 2007, 43, (9). 